\title{
Anti-PM/Scl antibodies are found in Japanese patients with various systemic autoimmune conditions besides myositis and scleroderma
}

\author{
Yoshinao Muro ${ }^{1,3^{*}}$, Yuji Hosono ${ }^{2}$, Kazumitsu Sugiura', Yasushi Ogawa', ${ }^{1}$ Tsuneyo Mimori ${ }^{2}$ and Masashi Akiyama'
}

\begin{abstract}
Introduction: Anti-PM/Scl antibodies are associated with polymyositis (PM)/systemic scleroderma (SSc) overlap syndromes and are also found in other systemic autoimmune diseases. Although anti-PM/SCl reactivity is found in $3-11 \%$ of PM or SSc patients and in approximately $25 \%$ of PM/SSc overlap patients, previous large studies of Japanese patients with scleroderma reported that anti-PM/Scl are not found in Japanese patients at all. The PM/Scl autoantigen complex comprises 11-16 different polypeptides; ELISA with PM1-a peptide, which is a major epitope of the PM/SCl complex, has frequently been used for the detection of these antibodies in recent studies. However, no ELISA kit is commercially available in Japan.
\end{abstract}

Methods: In this study, we developed an immunoassay for measuring antibodies against recombinant PM/Scl-100 and PM/Scl-75 polypeptides, which are the two major targets of the complex, and we investigated their presence in 600 Japanese patients with various systemic autoimmune conditions. Immunoprecipitation analysis using the recombinants in addition to traditional radiolabeled cell extracts were also applied to ELISA-positive sera.

Results: In ELISA, 11 patients were positive for anti-PM/Scl-100 antibodies and 7 of these 11 patients were also positive for anti-PM/Scl-75 antibodies. Immunoprecipitation analysis using the recombinants in addition to traditional radiolabeled cell extracts confirmed that 9 out of these 11 patients immunoprecipitated the typical sets of PM/Scl proteins. In total, 4/16 (25\%) undifferentiated connective tissue disease (UCTD) patients, 3/126 (2.4\%) dermatomyositis patients, 1/223 (0.4\%) SSc patients, 1/88 (1.1\%) Sjögren's syndrome patients, 0/123 patients with systemic lupus erythematosus, 0/17 patients with overlap syndrome and 0/7 patients with PM were judged to be positive for anti-PM/Scl antibodies.

Conclusions: This is the first report of Japanese autoimmune patients with anti-PM/Scl antibodies. In Japanese patients, anti-PM/Scl antibodies are only very rarely found, and they are not always specific for dermatomyositis (DM) or SSc; they are also present in various autoimmune conditions with the highest prevalence being in UCTD. All anti-PM/Scl-positive DM cases are complicated with interstitial lung disease and/or cancer, while no life-threatening involvement was found in other anti-PM/Scl-positive cases. Further studies on larger cohorts are necessary to define the clinical significance of anti-PM/Scl antibodies in autoimmune diseases.

\footnotetext{
* Correspondence: ymuro@med.nagoya-u.ac.jp

${ }^{1}$ Department of Dermatology, Nagoya University Graduate School of

Medicine, 65 Tsurumai-cho, Showa-ku, Nagoya 466-8550, Japan

${ }^{3}$ Division of Connective Tissue Disease and Autoimmunity, Department of

Dermatology, Nagoya University Graduate School of Medicine, 65

Tsurumai-cho, Showa-ku, Nagoya 466-8550, Japan

Full list of author information is available at the end of the article
} 


\section{Introduction}

A characteristic feature of patients with systemic autoimmune diseases is the presence of autoantibodies in their sera that target intracellular components [1]. Some of these autoantibodies are useful diagnostic markers for various systemic autoimmune diseases [1-3]. Some autoantibodies have great diversity in their prevalence among different races and countries [4-6].

Anti-PM/Scl antibodies, first described as 'anti-PM-1' in 1977, were found in patients with overlap syndrome of polymyositis (PM) and scleroderma (Scl) [7]. Anti-PM/Scl antibodies produce a homogenous nucleolar pattern in indirect immunofluorescence (IIF) staining and recognize the $\mathrm{PM} / \mathrm{Scl}$ complex, which is the human counterpart of the yeast exosome and consists of 11 to 16 polypeptides [8]. Most anti-PM/Scl antibodies recognize two components, PM/Scl-100 and PM/Scl-75 [9-11], and are found mostly in patients with overlap syndrome (OL) of PM and systemic scleroderma (SSc) (approximately 25\%) [12], as well as in PM or SSc patients (3\% to 13\%) [13]; however, they are rarely found in other diseases, such as Sjögren's syndrome (SS) [14]. For the detection of anti-PM/Scl antibodies, several techniques have been utilized: double immunodiffusion, immunoprecipitation (IPP), enzymelinked immunosorbent assay (ELISA) and line immunoassay (LIA) [15]. ELISA using the PM-1 $\alpha$ synthetic peptide, a major epitope of PM/Scl-100 composed of an alpha helical structure located at amino acid 231 to 245 of $\mathrm{PM} / \mathrm{Scl}-100$ [16], was used in a recent multicenter study that elucidated the diagnostic and prognostic relevance of anti-PM/Scl antibodies in SSc clinics [17]. Unfortunately, this ELISA kit is not available in Japan.

The frequencies of some autoantibodies vary by ethnicity. For example, in a U.S. SSc cohort, in AfricanAmerican patients, anti-U3-RNP (fibrillarin) antibodies were found in $30 \%$ of patients; meanwhile anti-Th/To antibodies were found in only $4 \%$ [4]. In white patients, however, anti-Th/To antibodies were found in $9 \%$, whereas anti-U3-RNP antibodies were found in only 3\% [4]. Another example is that anti-RNA polymerase III antibodies were less prevalent in French patients than in U.S. patients [7]. Although anti-PM/Scl antibodies are found in certain populations of patients in Western countries, as stated above, clinical studies on Japanese autoimmune patients to detect these antibodies have not been reported. Surprisingly, in two large SSc cohorts from two Japanese centers, no anti-PM/Scl-positive patients were found among 272 and 316 patients, respectively [18].

We recently developed a method that allows for the rapid conversion of cDNAs to a chemiluminescent ELISA to detect autoantibodies in human sera [19]. In this study, we constructed an ELISA for measuring anti-PM/Scl-100 and also anti-PM/Scl-75 antibodies, in order to screen these antibodies in 600 patients with various autoimmune conditions from a single center in Japan, and we investigated their clinical significance in Japanese patients.

\section{Methods}

\section{Serum samples}

Serum samples were collected from 600 Japanese patients, consisting of 223 with SSc, 126 with dermatomyositis (DM), 123 with systemic lupus erythematosus (SLE), 88 with SS, 17 with OL, 7 with PM and 16 with undifferentiated connective tissue disease (UCTD), between 1994 and 2014 at Nagoya University Hospital. SSc was diagnosed according to the classification of the American College of Rheumatology (ACR) [20] or the ACR/European League Against Rheumatism (EULAR) 2013 classification criteria [21]. Of the SSc patients, 185 were classified as diffuse cutaneous and 85 as limited cutaneous, according to the criteria of LeRoy and colleagues [22]. The DM patients (76 with adult DM, 12 with juvenile DM (JDM) and 38 with clinically amyopathic DM (CADM)) and PM patients fulfilled Bohan and Peter's criteria [23], except for CADM, which was defined by Sontheimer's criteria [24]. SLE was diagnosed by the ACR criteria for SLE [25]. SS was diagnosed based on Japanese diagnostic criteria [26]. OL, including 11 patients with $\mathrm{PM}+\mathrm{SSc}$, was diagnosed as cases that fulfilled the criteria for two systemic autoimmune diseases. UCTD was diagnosed according to the preliminary classification criteria proposed by Mosaca and colleagues [27]. Interstitial lung disease (ILD) was diagnosed by chest radiograph or chest computed tomography (CT) scan. Clinical information was collected retrospectively by reviewing their medical charts. Our cohort consisted of newly diagnosed incipient patients, except for a few patients with juvenile DM. As for patients with UCTD, serum samples were collected at the first visit. These patients were confirmed, by follow-up with doctors, as not fulfilling the criteria for defined CTD for at least three years from the beginning of symptoms according to the criteria of UCTD [27]. As control samples, serum samples from 72 healthy volunteers were also used. This study was conducted with the approval of the ethics committees of the Nagoya University Graduate School of Medicine and the Kyoto University Graduate School of Medical Science. All patients gave written consent to participate in the study.

Recombinant antigens for ELISA and immunoprecipitation The full-length cDNA clones of PM/Scl-100 (product No. FXC03779) and PM/Scl-75 (product No. FXC22044) were purchased from Flexi ${ }^{\bullet}$ ORF Clone (Promega, Madison, WI, USA). Biotinylated recombinant proteins were produced from the cDNA, using the T7 Quick Coupled Transcription/Translation System (Promega) according to our published protocol [28]. In short, $800 \mu \mathrm{l}$ transcription 
and translation (TnT) Quick Master Mix, $20 \mu \mathrm{l} 1 \mathrm{mM}$ methionine, $30 \mu \mathrm{l}$ transcend biotin-lysyl-tRNA, $120 \mu \mathrm{l}$ water and $30 \mu \mathrm{l}$ DNA $(1 \mu \mathrm{g} / \mu \mathrm{l})$ were mixed and then incubated at $30^{\circ} \mathrm{C}$ for 60 minutes.

\section{ELISA}

Antibodies against PM/Scl-100 and PM/Scl-75 were tested by antigen-capture ELISA according to our published protocols [19]. Briefly, a 96-well Nunc ${ }^{\mathrm{Tx}}$ Immobilizer $^{\mathrm{Tm}}$ Streptavidin Plate (Thermo Scientific Nunc, Roskilde, Denmark) was incubated with $1 \mu \mathrm{l} /$ well of in vitro TnT reaction mixture including biotinylated recombinant protein. Wells were then incubated with 1:1000 diluted sera and probed with anti-human immunoglobulin G (IgG) antibody conjugated with horseradish peroxidase (HRP) (Dako, Glostrup, Denmark) (1:30,000 dilution). After incubation with SuperSignal ${ }^{\circ}$ ELISA Femto Maximum Sensitivity Substrate (Thermo Scientific Pierce, Rockford, IL, USA), the relative luminescence unit (RLU) was determined using the GloMax-Multi Detection System (Promega). Each serum sample was tested in duplicate, and the mean RLU with the background subtracted was used for data analysis. The RLU of the samples was converted into units using a standard curve created by a prototype positive serum. As a standard, the high-titer anti-PM/Scl-100 (patient A in Figure 1) or anti-PM/Scl-75 (patient $\mathrm{E}$ in Figure 1) antibody-positive sera diluted 1:5 serially, starting from 1:500, was run. Units correlated with the titers of antibodies: 1:500 dilution, 625 units; 1:2,500, 125 units; 1:12,500, 25 units; 1:62,500, 5 units; 1:312,500, 1 unit; 1:1,562,500, 0.2 units. The cutoff values (4.4 units for anti-PM/Scl-100 antibody and 2.1 units for anti-PM/Scl75 antibody) were determined as the mean of the units obtained from 36 control sera from healthy volunteers +5 standard deviations (SD).

\section{Immunoprecipitation}

IPP was performed using TnT products as previously described [28] and using radiolabeled extracts of HeLa cells [29]. Prototype sera containing anti-PM/Scl, antiMDA5, anti-TIF1Y or anti-Mi-2 antibodies from TM's laboratory were also used.

\section{Laboratory tests and serological assay}

Sera that were positive for anti-PM/Scl by ELISA were analyzed with an IIF laboratory kit using HEp-2 cells (Fluoro HEPANA Test; MBL, Nagoya, Japan) [30]. The samples were also screened by ELISA for antibodies against CCP, SS-A, SS-B, U1-RNP, Sm, CENP-B, ribosomal $P$, aminoacyl tRNA synthetase (ARS) and ds-DNA with commercial kits (MBL, Nagoya, Japan). This antiSS-A kit detects only anti-SS-A/Ro60 and not anti-SSA/Ro52/TRIM21.

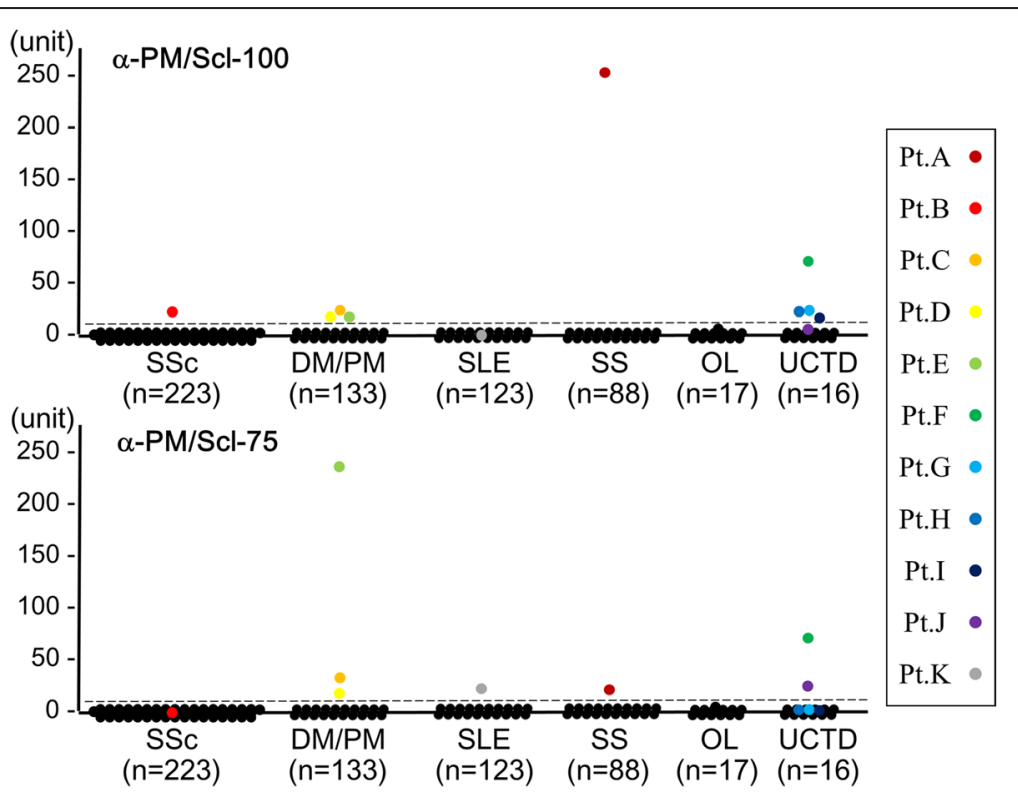

Figure 1 Qualitative measurement of anti-PM/SCl antibodies in ELISA. ELISA units of anti-PM/SCl-100 and anti-PM/Scl-75 antibodies are shown for a total of 600 serum samples from patients with various diseases. The antibody units are calculated from relative luminescence units using a standard curve obtained from serial concentrations of serum samples: patient A's serum for anti-PM/Scl-100 ELISA and patient E's serum for anti-PM/Scl-75 ELISA. The broken line indicates the cutoff value, which is the mean value of 36 healthy controls +5 standard deviations. DM, dermatomyositis; OL, overlap syndrome; PM, polymyositis; SLE, systemic lupus erythematosus; SS, Sjögren's syndrome; SSC, systemic scleroderma; UCTD, undifferntiated connective tissue disease. 


\section{Statistical analyses}

Data were statistically evaluated using SPSS Statistics (IBM, Tokyo, Japan). Fisher exact probability tests were used for comparison of frequencies. Mann-Whitney U tests were used for comparison of ELISA units. $P$ values of less than 0.05 were considered significant.

\section{Results}

\section{Measurement of anti-PM/Scl antibodies by ELISA}

For the screening of anti-PM/Scl antibodies in large numbers of serum samples, we developed an ELISA system that uses biotinylated recombinant PM/Scl-100 and $\mathrm{PM} / \mathrm{Scl}-75$. We screened a total of 600 serum samples obtained from patients with various systemic autoimmune diseases and an additional 36 serum samples from healthy volunteers for both antibodies. Based on the cutoff levels at 5 SDs above the mean value, nine (1.5\%) and seven (1.2\%) patients were positive for antiPM/Scl-100 and anti-PM/Scl-75 antibodies, respectively (Figure 1). Five patients (A, C, D, E and F) had both antibodies, four (B, G, H and I) had only anti-PM/Scl-100 antibodies, and two ( $\mathrm{J}$ and $\mathrm{K}$ ) had only anti-PM/Scl-75 antibodies. When the cutoff was set at 3 SDs above the mean value, one sample from a patient ( $\mathrm{L}$ mentioned in Figure 2) with overlap syndrome was just below the cutoff for both antibodies. Subsequently, serum samples from these 12 patients were used for immunoprecipitation to confirm whether they were truly positive for the
anti-PM/Scl antibodies. An additional 36 samples from healthy volunteers showed levels below the cutoff for both antibodies.

\section{Immunoprecipitation using recombinant $\mathrm{PM} / \mathrm{Scl}$ protein and radiolabeled cellular protein}

After the initial screening by ELISA, we investigated antibodies against $\mathrm{PM} / \mathrm{Scl}$ in sera from 11 anti-PM/Scl-100 and/or anti-PM/Scl-75-positive patients and 1 equivocal patient for their ability to immunoprecipitate biotinylated recombinant $\mathrm{PM} / \mathrm{Scl}-100$ and $\mathrm{PM} / \mathrm{Scl}-75$ and radiolabeled cellular PM/Scl. All nine anti-PM/Scl-100-positive sera in ELISA immunoprecipitated biotinylated recombinant PM/ Scl-100, whereas five of the seven anti-PM/Scl-75-positive sera in ELISA immunoprecipitated biotinylated recombinant PM/Scl-75 (Figure 2, TnT-IPP). Sera that were anti-PM/Scl-75-positive in ELISA but -negative in IPP ( $\mathrm{J}$ and $\mathrm{K}$ ) were negative for anti-PM/Scl-100 antibodies in ELISA and IPP. Serum of patient L with equivocal ranges in both ELISAs immunoprecipitated neither recombinant PM/Scl-100 nor PM/Scl-75 (data not shown).

To determine whether the positive sera in ELISA immunoprecipitate the $\mathrm{PM} / \mathrm{Scl}$ complex, we applied conventional IPP using radiolabeled HeLa cell extract (Figure 2, HeLa-IPP). All nine sera (patients A to I) that had reacted with the recombinant $\mathrm{PM} / \mathrm{Scl}-100$ also immunoprecipitated a cellular $100-\mathrm{kDa}$ protein. Eight of these sera also immunoprecipitated a $75-\mathrm{kDa}$ protein,

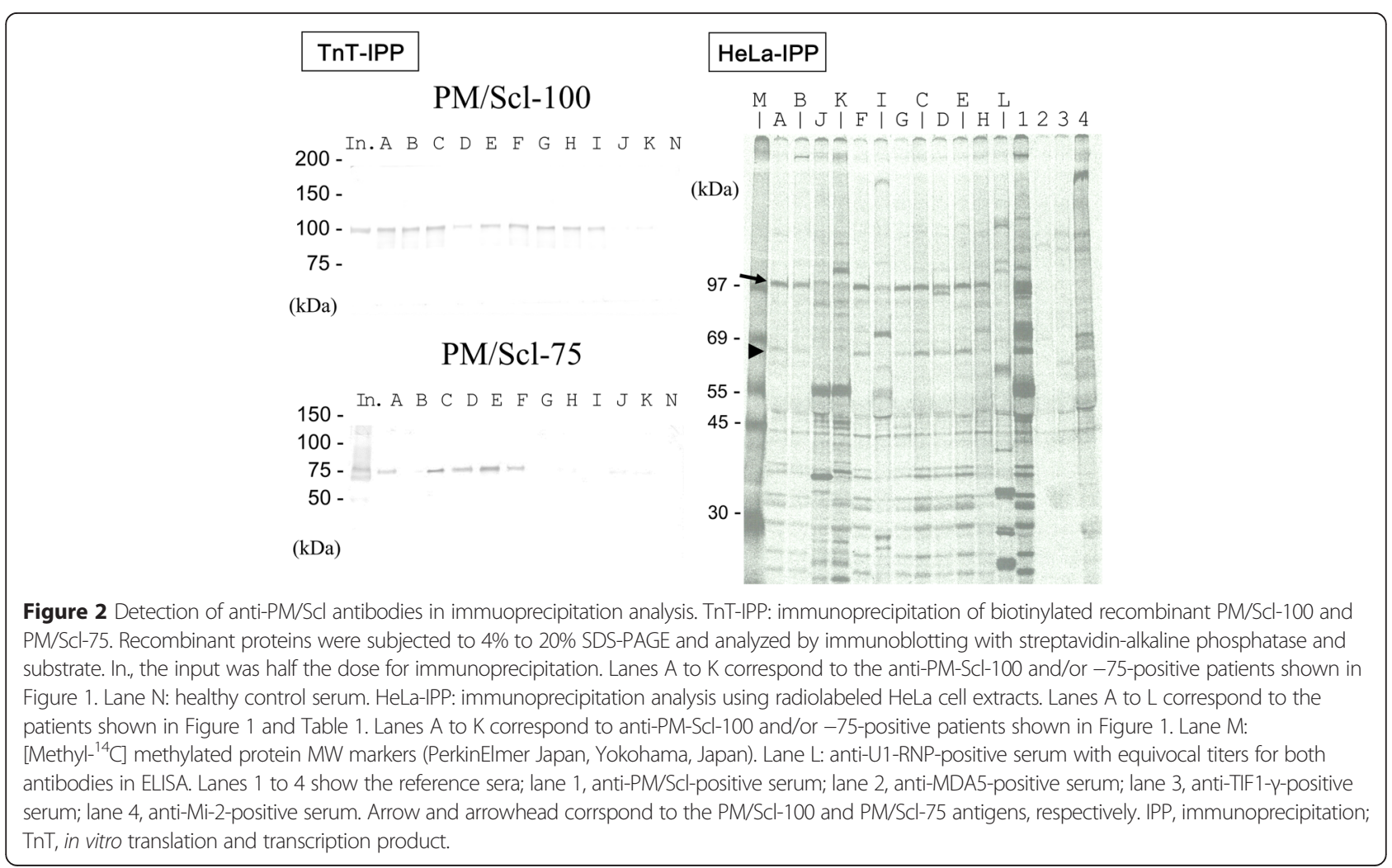


but one another (patient I) did not. Two sera that were positive only for anti-PM/Scl-75 in ELISA (patients J and $\mathrm{K}$ ) immunoprecipitated neither the $100-\mathrm{kDa}$ nor the $75-\mathrm{kDa}$ protein. The serum from an overlap syndrome patient (L) with an equivocal level of both anti-PM/Scl100/75 antibodies in ELISA was negative in IPP. According to these results, eight sera (patients $A$ to $H$ ) were judged to be positive for anti-PM/Scl antibodies, as was one other serum (patient I), which reacted to recombinant PM/Scl-100 and which immunoprecipitated a 100$\mathrm{kDa}$ cellular protein.

\section{Indirect immunofluorescence staining patterns of anti-PM/Scl-100 and/or anti-PM/Scl-75-positive sera} In IIF analysis, the eight sera (patients $A$ to $H$ ) that immunoprecipitated the $100-\mathrm{kDa}$ and $75-\mathrm{kDa}$ proteins showed nucleolar patterns (Table 1). The serum (patient I) that only immunoprecipitated the $100-\mathrm{kDa}$ protein showed a speckled pattern without nucleolar staining. Two sera (patients $\mathrm{J}$ and $\mathrm{K}$ ) that immunoprecipitated neither the $100-\mathrm{kDa}$ nor the $75-\mathrm{kDa}$ protein, also showed no nucleolar patterns.

\section{Clinical and laboratory data for anti-PM/Scl-positive patients}

The nine patients with anti-PM/Scl were four with UCTD, three with DM (including one with CADM), one with limited cutaneous SSc and one with SS. The clinical features of these patients are summarized in Table 1. The prevalence of anti-PM/Scl in UCTD (25\%) is significantly higher than that of DM $(2.4 \%, P=0.0032)$, SSc $(0.5 \%, P=0.000066)$, SS $(1.2 \%, P=0.0018)$, SLE $(0 \%, P=0.00012)$, OL $(0 \%, P=0.045)$ and healthy control $(0 \%, P=0.0067)$. Although the numbers of examined sera are very small, no patients with anti-PM/Scl antibodies are found among patients with PM or OL. Four patients with UCTD are clinically heterogeneous; two are suspected of having SLE, one of having SS and one of having rheumatoid arthritis (RA). All but one are young adult women. No common clinical features, including Raynaud's phenomenon and abnormal nailfold capillaries, are present among these four patients.

Of the $126 \mathrm{DM}$ patients, there are 8 anti-nucleolar antibody (ANoA)-positive patients, of whom 3 patients, all men, had anti-PM/Scl antibodies. Of the 123 anti-PM/ Scl-negative DM patients, only 32 are men $(P=0.020)$. These three patients were complicated with ILD. The clinical manifestations of ILD for these three patients were improved by oral prednisolone and immunosuppressive agent therapy, and their ILD did not have a fatal outcome. Additionally, the complication of internal malignancy (mesopharynx and prostate) was also recognized in two patients three years before or after the disease onset. ILD and internal malignancy are

Table 1 Connective tissue disease manifestations of anti-PM/Scl-100-ELISA- and/or anti-PM/Scl-75-ELISA-positive patients

\begin{tabular}{|c|c|c|c|c|c|c|c|c|c|}
\hline Patient & $\begin{array}{l}\text { Age in } \\
\text { years }\end{array}$ & $\begin{array}{l}\text { Sex } \\
M / F\end{array}$ & Diagnosis & IIF pattern ${ }^{a}$, titer & $\begin{array}{l}\text { ELISA } \\
\mathrm{PM} / \mathrm{Scl}-100 / \\
\mathrm{PM} / \mathrm{Scl}-75\end{array}$ & $\begin{array}{l}\text { TnT-IPP } \\
\text { PM/Scl-100/ } \\
\text { PM/Scl-75 }\end{array}$ & $\begin{array}{l}\text { HeLa-IPP } \\
\text { PM/Scl-100/ } \\
\text { PM/Scl-75 }\end{array}$ & $\begin{array}{l}\text { other auto- } \\
\text { antibodies }\end{array}$ & clinical features \\
\hline A & 52 & $\mathrm{~F}$ & SS & nucleolar, 1:2560 & $+1+$ & $+1+$ & $+1+$ & & dry eye, dry mouth \\
\hline B & 62 & $\mathrm{~F}$ & ISSC & nucleolar, 1:320 & $+/-$ & $+/-$ & $+1+$ & & Raynaud's ph, sclerodactyly \\
\hline C & 54 & M & CADM & $\begin{array}{l}\text { nucleolar, 1:640 } \\
\text { diffuse, 1:80 }\end{array}$ & $+1+$ & $+1+$ & $+1+$ & & $\begin{array}{l}\text { ILD, Gottron papules, } \\
\text { mechanic's hands }\end{array}$ \\
\hline $\mathrm{D}$ & 69 & M & $\mathrm{DM}$ & $\begin{array}{l}\text { nucleolar, 1:640 } \\
\text { diffuse, 1:80 }\end{array}$ & $+1+$ & $+1+$ & $+1+$ & & $\begin{array}{l}\text { ILD, Gottron sign, mechanic's } \\
\text { hands, V-neck sign, dysphagia, } \\
\text { pharyngeal Ca }\end{array}$ \\
\hline E & 67 & M & $\mathrm{DM}$ & nucleolar, 1:1280 & $+1+$ & $+1+$ & $+1+$ & & $\begin{array}{l}\text { ILD, Gottron sign, Heliotrope rash } \\
\text { muscle weakness, prostate } \mathrm{Ca}\end{array}$ \\
\hline $\mathrm{F}$ & 73 & F & UCTD & nucleolar, 1:640 & $+1+$ & $+1+$ & $+1+$ & & ILD, dry eye, dry mouth \\
\hline G & 33 & $\mathrm{~F}$ & UCTD & $\begin{array}{l}\text { nucleolar, 1:640 } \\
\text { diffuse, 1:80 }\end{array}$ & $+/-$ & $+/-$ & $+1+$ & & morning stiffness, polyarthralgia \\
\hline $\mathrm{H}$ & 31 & F & UCTD & $\begin{array}{l}\text { nucleolar, 1:160 } \\
\text { speckled, 1:80 }\end{array}$ & $+/-$ & $+/-$ & $+1+$ & & polyarthralgia, photosensitivity \\
\hline । & 31 & $\mathrm{~F}$ & UCTD & speckled, 1:80 & $+1-$ & $+/-$ & $+1-$ & & oral ulcer, photosensitivity \\
\hline J & 24 & $\mathrm{~F}$ & UCTD & $\begin{array}{l}\text { diffuse, 1:640 } \\
\text { cytoplasmic, 1:160 }\end{array}$ & $-1+$ & $-/-$ & $-/-$ & SS-A & dry eye, dry mouth \\
\hline K & 23 & F & SLE & $\begin{array}{l}\text { diffuse, 1:320 } \\
\text { cytoplasmic, 1:80 }\end{array}$ & $-1+$ & $-1-$ & $-/-$ & $\begin{array}{l}\text { SS-A } \\
\text { ribosomal P }\end{array}$ & $\begin{array}{l}\text { polyarthralgia, malar rash, } \\
\text { photosensitivity, leukopenia }\end{array}$ \\
\hline
\end{tabular}

a 'diffuse' and 'speckled' in the IIF pattern, respectively, refer to nuclear diffuse and nuclear speckled patterns. CADM, clinically amyopathic DM; Ca, carcinoma; DM, dermatomyositis; ILD, interstitial lung disease; ISSc, limited cutaneous SSc; ph, phenomenon; SLE, systemic lupus erythematosus; SS, Sjögren's syndrome; SSc, systemic scleroderma; UCTD, undifferentiated connective tissue disease. 
more frequent in anti-PM/Scl-positive DM patients than in anti-PM/Scl-negative DM patients, but not significantly $(P=0.060$ and $P=0.072$, respectively).

Besides the three DM patients with ILD, one patient who had UCTD was also complicated with ILD. Although the anti-PM/Scl-100 ELISA units of these four patients with ILD were not higher than those of five anti-PM/Scl-positive patients without ILD (mean 26.7 versus 62.0), anti-PM/Scl-75 titers of the four patients with ILD were significantly higher than those of five patients without ILD (mean 86.0 unit versus 0.96 unit, $P=0.027$ by Mann-Whitney $U$ test).

\section{Discussion}

The anti-PM/Scl antibody is a well-known ANoA and a serological marker of $\mathrm{OL}$ and other systemic autoimmune diseases such as SSc, PM and DM alone [15]. This antibody is common in the West. For example, it

Table 2 Frequencies of anti-PM/Scl antibodies in disease subsets

\begin{tabular}{|c|c|c|c|c|c|c|}
\hline \multicolumn{7}{|c|}{ Frequencies of anti-PM/Scl antibodies in disease subsets } \\
\hline Study & Marguerie & Mahler & Rozman & \multicolumn{2}{|l|}{ Hanke } & Maes \\
\hline Reference & [13] & [39] & {$[40]$} & \multicolumn{2}{|l|}{ [41] } & [42] \\
\hline Year & 1992 & 2005 & 2008 & \multicolumn{2}{|l|}{2009} & 2010 \\
\hline Country & UK & Various & Europe & \multicolumn{2}{|l|}{ Germany } & Belgium \\
\hline Anti-PM/Scl detection & $\mathrm{ClE}$ & PM1-a ELISA & LIA & \multicolumn{2}{|l|}{ LIA } & PM1-a ELISA \\
\hline \multirow{7}{*}{$\begin{array}{l}\text { Patient selection and numbers } \\
\text { of patients }\end{array}$} & 1689 SLE & 205 SSC & 625 SSC & \multicolumn{2}{|l|}{$280 \mathrm{SSc}^{\mathrm{b}}$} & $70 \mathrm{SSC}$ \\
\hline & 879 SSC $^{\mathrm{a}}$ & 114 SLE & & \multicolumn{2}{|l|}{$88 \mathrm{RA}$} & 66 SLE \\
\hline & $256 \mathrm{PM}$ or DM & $40 \mathrm{PM}$ & & \multicolumn{2}{|l|}{72 SLE } & 35 SS \\
\hline & & \multicolumn{2}{|l|}{$40 \mathrm{PM} / \mathrm{SSC}$} & \multicolumn{2}{|l|}{49 SS } & $24 \mathrm{RA}$ \\
\hline & & & & & & $23 \mathrm{DM}$ \\
\hline & & & & & & 13 PM \\
\hline & & & & & & 11 MCTD \\
\hline \multirow[t]{4}{*}{ Anti-PM/Scl-positive patients } & $27 \mathrm{PM}$ (or DM)/SSC & $22 \mathrm{PM} / \mathrm{SSC}(55 \%)$ & 1 PM (7.7\%) & Anti-PM/Scl-75 & Anti-PM/Scl-100 & \multirow[t]{4}{*}{3 SSc (4.3\%) } \\
\hline & $4 \mathrm{SSC}$ & 27 SSc (13\%) & 18 SSc (2.9\%) & 29 SSc (10\%) & 20 SSc (7.1\%) & \\
\hline & \multirow[t]{2}{*}{$1 \mathrm{PM}$} & \multirow[t]{2}{*}{3 PM (7.5\%) } & \multirow[t]{2}{*}{$1 \mathrm{DM}(1.7 \%)$} & 3 RA (3.4\%) & 3 SLE (4.2\%) & \\
\hline & & & & 1 SLE (1.4\%) & 1 SS (2.0\%) & \\
\hline Study & Mierau & Koschik & Mehra & D'Aoust & Kazi & Muro \\
\hline Reference & [31] & [57] & {$[58]$} & [17] & [18] & The present study \\
\hline Year & 2011 & 2012 & 2013 & 2014 & 2014 & \\
\hline Country & Germany & USA & Australia & Canada & Japan & Japan \\
\hline Anti-PM/Scl detection & ID & ID & LIA & PM1-a ELISA & $\| P$ & ELISA, IPP \\
\hline \multirow{7}{*}{$\begin{array}{l}\text { Patient selection and numbers } \\
\text { of patients }\end{array}$} & \multirow[t]{7}{*}{863 SSC } & \multirow[t]{7}{*}{2425 SSC } & $528 \mathrm{SSC}$ & \multirow[t]{7}{*}{763 SSC } & Kanazawa cohort & 223 SSC \\
\hline & & & & & 316 SSC & $126 \mathrm{DM}$ \\
\hline & & & & & Keio cohort & $123 \mathrm{SLE}$ \\
\hline & & & & & 272 SSC & $88 \mathrm{SS}$ \\
\hline & & & & & & 17 overlap \\
\hline & & & & & & 16 UCTD \\
\hline & & & & & & $7 \mathrm{PM}$ \\
\hline \multirow[t]{4}{*}{ Anti-PM/Scl-positive patients } & \multirow[t]{4}{*}{$42 \operatorname{SSc}(4.9 \%)$} & \multirow[t]{4}{*}{75 SSc (3.1\%) } & Anti-PM/Scl-75 & \multirow[t]{4}{*}{$55 \operatorname{SSc}(7.2 \%)$} & \multirow[t]{4}{*}{0} & 4 UCTD (25\%) \\
\hline & & & 66 SSC (12.5\%) & & & $3 \mathrm{DM}(2.4 \%)$ \\
\hline & & & Anti-PM/Scl-100 & & & 1 SS (1.1\%) \\
\hline & & & 26 SSC (4.9\%) & & & $1 \mathrm{SSC}(0.4 \%)$ \\
\hline
\end{tabular}

${ }^{\mathrm{a}}$ Since the numbers of myositis overlap patients were not given, the frequencies of the antibodies in disease subsets were not calculated; ${ }^{\mathrm{b}} 51$ overlap and 16 undifferentiated connective tissue disease patients were included.

$\mathrm{CIE}$, counter immunoelectrophoresis; DM, dermatomyositis; ID, immunodiffusion; IPP, immunoprecipitation; LIA, line immunoassay; MCTD, mixed connective tissue disease; PM, polymyositis; RA, rheumatoid arthritis; SLE, systemic lupus erythematosus; SS, Sjögren's syndrome; SSc, systemic scleroderma; UCTD, undifferentiated connective tissue disease. 
was the third most-found, followed by anti-centromere and anti-topoisomerase I antibodies, in a large cohort of SSc patients in Germany [31]. However, large studies of Japanese patients with SSc showed this antibody to be absent [32,33], and a recent study noted that $0 / 588$ Japanese patients with SSc had anti-PM/Scl antibodies [18]. Large-cohort studies using sera from more than 200 connective tissue disease patients in the literature are summarized in Table 2, although some studies with mostly overlapped patients are omitted. Anti-PM/Scl antibodies are strongly linked to HLA-DRB1*0301 [34], which is very rarely found in Japanese, with a prevalence of only $0.14 \%$, according to an online database [35] (HLA Laboratory, Kyoto, Japan); however, the contribution of this finding remains unknown. Since we had found three patients to have strong ANoA in IIF analysis during our recent studies on myositis-specific or associated autoantibodies [36-38], we aimed to investigate anti-PM/Scl antibodies in our large cohort of systemic autoimmune disease.

Although LIA for anti-PM/Scl-75 and -100 antibodies and PM1- $\alpha$ ELISA have often been used recently $[16,31,39-43]$, the latter is not available in Japan and the former is not cost-effective, costing around 13,000 yen/ sample (Cosmic Corporation, Tokyo, Japan). For our inhouse ELISA, the anti-PM/Scl-75 assay was found to be inferior to the anti-PM/Scl-100 assay both in sensitivity and specificity, according to the results of protein-IPP, which is widely accepted as a reference method for detecting several markers for SSc and PM/DM. Originally, most $\mathrm{PM} / \mathrm{Scl}$-positive sera have been shown to contain anti$\mathrm{PM} / \mathrm{Scl}-100$ and about $50 \%$ to $60 \%$ of the sera have been shown to react with $\mathrm{PM} / \mathrm{Scl}-75[11,12,44,45]$. Raijmakers and colleagues showed that $\mathrm{PM} / \mathrm{Scl}-75$ contains a previously unidentified $\mathrm{N}$-terminal region that is important for the antigenicity of the protein [46]. This longer form, named $\mathrm{PM} / \mathrm{Scl}-75 \mathrm{c}$, was as reactive as $\mathrm{PM} / \mathrm{Scl}-100$ to sera from PM/SSc overlap patients in ELISA (28\% and 25\%, respectively) [46]. Subsequently, Hanke and colleagues showed the prevalence of anti-PM/Scl- $75 \mathrm{c}$ to be higher than that of anti-PM/Scl-100 (10.4\% versus $7.1 \%)$ in LIA using sera from 280 SSc patients [41]. There are several possible explanations for the lower prevalence of anti-PM/ Scl-75 than anti-PM/Scl-100 in this study. The cDNA in this study, PM/Scl-75c- $\beta$, has a 17 amino acid insertion at the C-terminus which could introduce conformational changes in epitope [47]. In the study of Hanke and colleagues, recombinant $\mathrm{PM} / \mathrm{Scl}-75$ was expressed by a baculovirus [41]. The discrepancies might also be due to racial differences or clinical backgrounds. In a validation study by Jaskowski and colleagues, the anti-PM/Scl-100 LIA had better agreement for the detection of anti-PM/Scl with IPP as the reference method than with PM/Scl-75 LIA and PM1- $\alpha$ ELISA [48].
In this study, eight of nine anti-PM/Scl antibodypositive sera exhibited nucleolar staining in IIF analysis. Some studies have shown that anti-PM/Scl-positive sera do not always demonstrate a nucleolar staining pattern in IIF $[16,17,47,49]$. Interestingly, one ANoA-negative serum with anti-PM/Scl reacted with $\mathrm{PM} / \mathrm{Scl}-100$ but not with $\mathrm{PM} / \mathrm{Scl}-75$. Intramolecular epitope spreading from the initial response against PM/Scl-100 to a successive response by other exosomal components has been recognized, as have many other autoantibody responses [50]. Figure 3 shows a four-way Venn diagram depicting the overlap between anti-PM/Scl-100 by TnTIPP, anti-PM/Scl-75 by TnT-IPP, anti-PM/Scl by cellular IPP and anti-nucleolar pattern by IIF. ANoA-positive anti-PM/Scl antibodies all immunoprecipitated both $100-$ and $75-\mathrm{kDa}$ proteins in HeLa-IPP, whereas only one ANoA-negative anti-PM/Scl antibody (patient I) immunoprecipitated only a $100-\mathrm{kDa}$ protein in HeLaIPP. Since sera from Patient I immunoprecipitated several other polypeptides, the nuclear speckled staining of this patient in IIF may correspond to antibodies against these proteins. Moreover, anti-PM1 $\alpha$ reactivity has been reported in apparently ANA-negative samples $[16,17,49]$. Although future studies are necessary to address whether monospecific anti-PM/Scl-100 antibodies show nucleolar staining in IIF, we can conclude that IIF is not a sensitive immunoassay for the detection or screening of anti-PM/ Scl antibodies.

The findings of anti-PM/Scl antibodies in UCTD patients are of clinical importance. The classification criteria of UCTD are not well established [51]. Since our UCTD patients were not diagnosed with definite

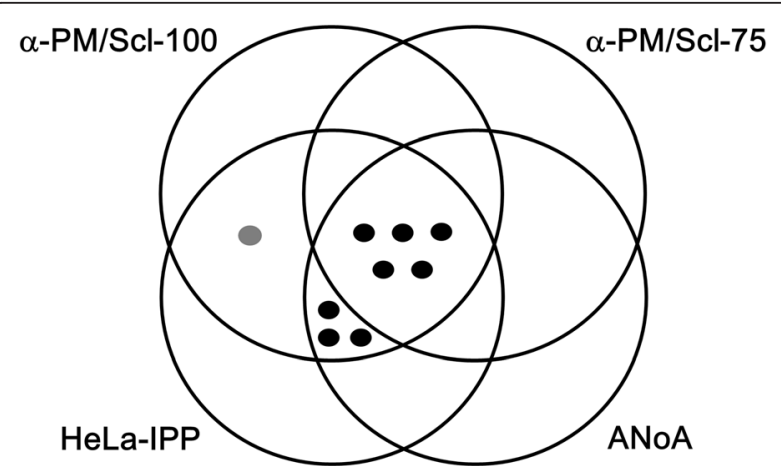

Figure 3 Venn diagram showing the overlap between anti-PM/SCl antibodies by different assays. Anti-PM/SCl-100 and anti-PM/Scl-75 circles show the antibody-positive patiens determined by

immunoprecipitation with the corresponding recombinant protein. The HeLa-IPP circle shows anti-PM/Scl-positive patients determined by immunoprecipitation with HeLa cellular protein. Black dots show the patients with both anti-75 kDa and anti-100 kDa antibodies, and the gray dot shows the patient with only anti-75 kDa antibody in HeLa-IPP. The ANoA circle shows the patients demonstrating anti-nucleolar patterns as observed by indirect immunofluorecence. 
connective tissue disease even if the new set of RA criteria [52] and the preliminary criteria for the very early diagnosis of SSc [53] were used, we applied the preliminary classification criteria of UCTD suggested by Mosca and colleagues [27]. Four UCTD patients with anti-PM/Scl were all so-called 'stable UCTD'. Their disease courses were stable over a period of more than three years without internal organ involvement, except for one, whose ILD was nonspecific interstitial pneumonia that did not exacerbate for more than ten years. Interestingly, Cordiali-Fei and colleagues [54] reported that anti-PM/Scl responses were mainly associated with Italian patients with UCTD, which was defined by the same criteria used in our study. They found 5 patients with anti-PM/Scl in 23 patients with UCTD (22\%), a frequency that is almost the same as that of our study.

Of second importance are the three anti-PM/Sclpositive DM patients. Myalgia or muscle weakness varied, and the levels of creatine kinase ranged from normal levels to more than 2,000 IU/L. Patient C in this study is the second reported case of CADM, to the best of our knowledge, following the first case described by Lega and colleagues [55]. A previous study of $20 \mathrm{PM} / \mathrm{DM}$ patients with anti-PM/Scl demonstrated that anti-PM-Scl is not necessarily a marker for good prognosis in patients with $\mathrm{PM} / \mathrm{DM}$, because lung and esophageal involvement were found (in $75 \%$ and $20 \%$, respectively), as was internal malignancy (in 15\%) [56]. Also in our study, all three patients were complicated with ILD and required combined therapy of steroids and immunosuppressive agents. Although they were all alive during the observation periods, the prognosis of ILD in anti-PM/Scl-positive DM patients cannot be determined due to the very limited numbers examined and the limited observation periods (maximum 45 months). Two of these patients were also complicated with localized cancer without metastasis. In a previous study, two out of twelve antibodypositive patients with DM had mechanic's hands [56]. Very interestingly, also in our study, two patients exhibited mechanic's hands in addition to sole hyperkeratotic rhagadiform symptoms.

\section{Conclusions}

Our study of Japanese patients with various systemic autoimmune diseases confirms that anti-PM/Scl antibodies also exist in these patients. ELISA with PM/Scl-100 recombinant protein was useful in detecting anti-PM/Scl antibodies. Anti-PM/Scl was not always specific for DM or SSc; it was also present in various autoimmune conditions, including UCTD. All the anti-PM/Scl-positive DM cases were complicated with ILD and/or cancer, while no life-threatening internal organ involvement was found in other anti-PM/Scl-positive cases. Considering the higher prevalence of anti-PM/Scl in UCTD, this autoantibody may be more important in systemic autoimmune disease clinics than we expected. Further studies in larger cohorts are necessary to define the clinical significance of anti-PM/Scl antibodies in Japanese patients with each autoimmune condition. Future collaborative studies for evaluating our sera with LIA and PM- $1 \alpha$ ELISA promise to be interesting.

\section{Abbreviations}

ACR: American College of Rheumatology; ANoA: anti-nucleolar antibody; ARS: aminoacyl tRNA synthetase; CADM: clinically amyopathic dermatomyositis; CIE: counter immunoelectrophoresis; DM: dermatomyositis; ELISA: enzymelinked immunosorbent assay; EULAR: European League Against Rheumatism; ID: immunodiffusion; IIF: indirect immunofluorescence; ILD: interstitial lung disease; IPP: immunoprecipitation; LIA: line immunoassay; OL: overlap syndrome; PM: polymyositis; RA: rheumatoid arthritis; RLU: relative luminescence unit; Scl: scleroderma; SD: standard deviation; SLE: systemic lupus erythematosus; SS: Sjögren's syndrome; SSc: systemic sclerosis; TnT: in vitro translation and transcription product; UCTD: undifferentiated connective tissue disease.

\section{Competing interests}

The authors declare that they have no competing interests.

\section{Authors' contributions}

YM performed the serological analyses and the analysis of the data. YH and TM performed immunoprecipitation with the radiolabeled extract and interpreted the data. KS and YO provided sera for the analyses. MA made intellectual contributions and helped to prepare the manuscript. All authors were involved in the conception, design, and interpretation of data and in drafting the article and revising it critically for important intellectual content. All authors read and approved the final manuscript.

\section{Acknowledgements}

The authors thank Rie Yamamoto and Sayuri Morita for their technical assistance. Written informed consent was obtained from the patients for publication of their individual details in this manuscript. The consent form is held by the authors and is available for review by the Editor-in-Chief.

\section{Author details}

'Department of Dermatology, Nagoya University Graduate School of Medicine, 65 Tsurumai-cho, Showa-ku, Nagoya 466-8550, Japan. ${ }^{2}$ Department of Rheumatology and Clinical Immunology, Kyoto University Graduate School of Medicine, Sakyo-ku, Kyoto 606-8507, Japan. ${ }^{3}$ Division of Connective Tissue Disease and Autoimmunity, Department of Dermatology, Nagoya University Graduate School of Medicine, 65 Tsurumai-cho, Showa-ku, Nagoya 466-8550, Japan.

Received: 18 October 2014 Accepted: 20 February 2015

Published online: 11 March 2015

\section{References}

1. Tan EM. Antinuclear antibodies: diagnostic markers for autoimmune diseases and probes for cell biology. Adv Immunol. 1989;44:93-151.

2. Muro Y. Antinuclear antibodies. Autoimmunity. 2005;38:3-9.

3. Satoh M, Vazquez-Del Mercardo M, Chan EKL. Clinical interpretation of antinuclear antibody tests in systemic rheumatic diseases. Mod Rheumatol. 2009;19:219-28.

4. Krzyszczak ME, Li Y, Ross SJ, Ceribelli A, Chan EK, Bubb MR, et al. Gender and ethnicity differences in the prevalence of scleroderma-related autoantibodies. Clin Rheumatol. 2011;30:1333-9.

5. Meyer O, De Chaisemartin L, Nicaise-Roland P, Cabane J, Tubach F, Dieude $P$, et al. Anti-RNA polymerase III antibody prevalence and associated clinical manifestations in a large series of French patients with systemic sclerosis: a cross-sectional study. J Rheumatol. 2010;37:125-30.

6. Petri MH, Satoh M, Martin-Marquez BT, Vargas-Ramirez R, Jara LJ, Saavedra MA, et al. Implications in the difference of anti-Mi-2 and -p155/140 autoantibody prevalence in two dermatomyositis cohorts from Mexico City and Guadalajara. Arthritis Res Ther. 2013;15:R48. 
7. Wolfe JF, Adelstein E, Sharp GC. Antinuclear antibody with distinct specificity for polymyositis. J Clin Invest. 1977;59:176-8.

8. Schilders G, van Dijk E, Raijmakers R, Pruijn GJ. Cell and molecular biology of the exosome: how to make or break an RNA. Int Rev Cytol. 2006;251:159-208.

9. Alderuccio F, Chan EK, Tan EM. Molecular characterization of an autoantigen of PM-Scl in the polymyositis/scleroderma overlap syndrome: a unique and complete human cDNA encoding an apparent 75-kD acidic protein of the nucleolar complex. J Exp Med. 1991;173:941-52.

10. Bluthner M, Bautz FA. Cloning and characterization of the cDNA coding for a polymyositis-scleroderma overlap syndrome-related nucleolar 100-kD protein. J Exp Med. 1992;176:973-80.

11. Ge Q, Frank MB, O'Brien C, Targoff IN. Cloning of a complementary DNA coding for the $100-\mathrm{kD}$ antigenic protein of the PM-Scl autoantigen. J Clin Invest. 1992;90:559-70.

12. Reimer $G$, Scheer $U$, Peters JM, Tan EM. Immunolocalization and partial characterization of a nucleolar autoantigen (PM-SCl) associated with polymyositis/scleroderma overlap syndromes. J Immunol. 1986;137:3802-8.

13. Marguerie C, Bunn CC, Copier J, Bernstein RM, Gilroy JM, Black CM, et al. The clinical and immunogenetic features of patients with autoantibodies to the nucleolar antigen PM-Scl. Medicine (Baltimore). 1992;71:327-36.

14. Vandergheynst F, Ocmant A, Sordet C, Humbel RL, Goetz J, Roufosse F, et al. Anti-pm/scl antibodies in connective tissue disease: clinical and biological assessment of 14 patients. Clin Exp Rheumatol. 2006:24:129-33.

15. Mahler M, Raijmakers R. Novel aspects of autoantibodies to the PM/SC complex: clinical, genetic and diagnostic insights. Autoimmun Rev. 2007;6:432-7.

16. Mahler M, Fritzler MJ. PM1-Alpha ELISA: the assay of choice for the detection of anti-PM/Scl autoantibodies? Autoimmun Rev. 2009;8:373-8.

17. D'Aoust J, Hudson M, Tatibouet S, Wick J. Canadian Scleroderma Research Group, Mahler M, et al. Clinical and serologic correlates of anti-PM/SCl antibodies in systemic sclerosis: a multicenter study of 763 patients. Arthritis. Rheumatol. 2014;66:1608-15.

18. Kaji K, Fertig N, Medsger Jr TA, Satoh T, Hoshino K, Hamaguchi Y, et al. Autoantibodies to RuvBL1 and RuvBL2: a novel systemic sclerosis-related antibody associated with diffuse cutaneous and skeletal muscle involvement. Arthritis Care Res (Hoboken). 2014;66:575-84.

19. Muro Y, Sugiura K, Akiyama M. A new ELISA for dermatomyositis autoantibodies: rapid introduction of autoantigen cDNA to recombinant assays for autoantibody measurement. Clin Dev Immunol. 2013;2013:856815.

20. Subcommittee for Scleroderma Criteria of the American Rheumatism Association Diagnostic and Therapeutic Criteria Committee. Preliminary criteria for the classification of systemic sclerosis (scleroderma). Arthritis Rheum. 1980;23:581-90.

21. van den Hoogen F, Khanna D, Fransen J, Johnson SR, Baron M, Tyndall A, et al. 2013 classification criteria for systemic sclerosis: an American College of Rheumatology/European League against Rheumatism collaborative initiative. Arthritis Rheum. 2013;65:2737-47.

22. LeRoy EC, Black C, Fleischmajer R, Jablonska S, Krieg T, Medsger Jr TA, et al, Scleroderma (systemic sclerosis): classification, subsets and pathogenesis. J Rheumatol. 1988;15:202-5.

23. Bohan A, Peter JB. Polymyositis and dermatomyositis. N Engl J Med. 1975;292:344-7.

24. Sontheimer RD. Would a new name hasten the acceptance of amyopathic dermatomyositis (dermatomyositis sine myositis) as a distinctive subset within the idiopathic inflammatory dermatomyopathies spectrum of clinical illness? J Am Acad Dermatol. 2002;46:626-36.

25. Tan EM, Cohen AS, Fries JF, Masi AT, McShane DJ, Rothfield NF, et al. The 1982 revised criteria for the classification of systemic lupus erythematosus. Arthritis Rheum. 1982:25:1271-7.

26. Fujibayashi T, Sugai S, Miyasaka N, Hayashi Y, Tsubota K. Revised Japanese criteria for Sjögren's syndrome (1999): availability and validity. Mod Rheumatol. 2004;14:425-34

27. Mosca M, Neri R, Bombardieri S. Undifferentiated connective tissue disease (UCTD): a review of the literature and a proposal for preliminary classification criteria. Clin Exp Rheumatol. 1999;17:615-20.

28. Hoshino K, Muro Y, Sugiura K, Tomita Y, Nakashima R, Mimori T. Anti-MDA5 and anti-TIF1-gamma antibodies have clinical significance for patients with dermatomyositis. Rheumatology (Oxford). 2010;49:1726-33.

29. Nakashima R, Imura Y, Kobayashi S, Yukawa N, Yoshifuji H, Nojima T, et al. The RIG-l-like receptor IFIH1/MDA5 is a dermatomyositis-specific autoantigen identified by the anti-CADM-140 antibody. Rheumatology (Oxford). 2010;49:433-40
30. Watanabe A, Kodera M, Sugiura K, Usuda T, Tan EM, Takasaki Y, et al. Anti-DFS70 antibodies in 597 healthy hospital workers. Arthritis Rheum. 2004,50:892-900

31. Mierau R, Moinzadeh P, Riemekasten G, Melchers I, Meurer M, Reichenberger F, et al. Frequency of disease-associated and other nuclear autoantibodies in patients of the German Network for Systemic Scleroderma: correlation with characteristic clinical features. Arthritis Res Ther. 2011;13:R172.

32. Kuwana M, Kaburaki J, Okano Y, Tojo T, Homma M. Clinical and prognostic associations based on serum antinuclear antibodies in Japanese patients with systemic sclerosis. Arthritis Rheum. 1994;37:75-83.

33. Hamaguchi $Y$, Hasegawa M, Fujimoto M, Matsushita T, Komura K, Kaji K, et al. The clinical relevance of serum antinuclear antibodies in Japanese patients with systemic sclerosis. Br J Dermatol. 2008;158:487-95.

34. Hausmanowa-Petrusewicz I, Kowalska-Oledzka E, Miller FW, JarzabekChorzelska M, Targoff IN, Blaszczyk-Kostanecka M, et al. Clinical, serologic and immunogenetic features in Polish patients with idiopathic inflammatory myopathies. Arthritis Rheum. 1997:40:1257-66.

35. HLA laboratory. Haplotype/ allele Freq. http://hla.or.jp/haplo/ haplonavi.php?type=aril\&lang=en

36. Ishikawa A, Muro Y, Sugiura K, Akiyama M. Development of an ELISA for detection of autoantibodies to nuclear matrix protein 2. Rheumatology (Oxford). 2012;51:1181-7.

37. Muro Y, Ishikawa A, Sugiura K, Akiyama M. Clinical features of anti-TIF1-a antibody-positive dermatomyositis patients are closely associated with coexistent dermatomyositis-specific autoantibodies and anti-TIF1-y or anti-Mi-2 autoantibodies. Rheumatology (Oxford). 2012;51:1508-13.

38. Muro Y, Nakashima R, Hosono Y, Sugiura K, Mimori T, Akiyama M. Autoantibodies to DNA mismatch repair enzymes in polymyositis/ dermatomyositis and other autoimmune diseases: a possible marker of favorable prognosis. Arthritis Rheumatol. 2014;66:3457-62.

39. Mahler M, Raijmakers R, Dähnrich C, Blüthner M, Fritzler MJ. Clinical evaluation of autoantibodies to a novel PM/Scl peptide antigen. Arthritis Res Ther. 2005;7:R704-13.

40. Rozman B, Cucnik S, Sodin-Semrl S, Czirják L, Varjú C, Distler O, et al. Prevalence and clinical associations of anti-Ku antibodies in patients with systemic sclerosis: a European EUSTAR-initiated multi-centre case-contro study. Ann Rheum Dis. 2008;67:1282-6.

41. Hanke K, Brückner CS, Dähnrich C, Huscher D, Komorowski L, Meyer W, et al. Antibodies against PM/SCl-75 and PM/SCl-100 are independent markers for different subsets of systemic sclerosis patients. Arthritis Res Ther. 2009;11:R22.

42. Maes L, Blockmans D, Verschueren P, Westhovens R, De Beéck KO, Vermeersch P, et al. Anti-PM/SCl-100 and anti-RNA-polymerase III antibodies in scleroderma. Clin Chim Acta. 2010:411:965-71.

43. Koenig M, Fritzler MJ, Targoff IN, Troyanov Y, Senécal JL. Heterogeneity of autoantibodies in 100 patients with autoimmune myositis: insights into clinical features and outcomes. Arthritis Res Ther. 2007;9:R78.

44. Gelpi C, Algueró A, Angeles Martinez M, Vidal S, Juarez C, RodriguezSanchez $J$. Identification of protein components reactive with anti-PM/SCl autoantibodies. Clin Exp Immunol. 1990:81:59-64.

45. Brouwer R, Vree Egberts WT, Hengstman GJ, Raijmakers R, van Engelen BG, Seelig HP, et al. Autoantibodies directed to novel components of the PM/Scl complex, the human exosome. Arthritis Res. 2002;4:134-8.

46. Raijmakers R, Renz M, Wiemann C, Egberts WV, Seelig HP, van Venrooij WJ, et al. PM-SCl-75 is the main autoantigen in patients with the polymyositis/ scleroderma overlap syndrome. Arthritis Rheum. 2004;50:565-9.

47. Raijmakers R, Egberts WV, van Venrooij WJ, Pruijn GJ. The association of the human PM/SCl-75 autoantigen with the exosome is dependent on a newly identified N terminus. J Biol Chem. 2003;278:30698-704.

48. Jaskowski TD, Wilson A, Hill HR, Tebo AE. Diagnostic assays for anti-PM/SCl IgG antibodies: heterogeneity in antibody response or lack of standardization? Clin Chim Acta. 2011;412:1100-5.

49. D'Aoust J, Hudson M, Mahler M, Baron M, Fritzler MJ. Additional reasons to measure anti-PM1-Alpha antibodies in systemic sclerosis. Arthritis Rheumatol. 2014. doi: 10.1002/art.38801.

50. Gutiérrez-Ramos R, Gonz Lez-Díaz V, Pacheco-Tovar MG, López-Luna A, Avalos-Díaz E, Herrera-Esparza R. A dermatomyositis and scleroderma overlap syndrome with a remarkable high titer of anti-exosome antibodies. Reumatismo. 2008;60:296-300.

51. Mosca M, Tani C, Vagnani S, Carli L, Bombardieri S. The diagnosis and classification of undifferentiated connective tissue diseases. J Autoimmun. 2014;48-49:50-2. 
52. Aletaha D, Neogi T, Silman AJ, Funovits J, Felson DT, Bingham 3rd CO, et al. 2010 rheumatoid arthritis classification criteria: an American College of Rheumatology/European League Against Rheumatism collaborative initiative. Ann Rheum Dis. 2010;69:1580-8.

53. Avouac J, Fransen J, Walker UA, Riccieri V, Smith V, Muller C, et al. Preliminary criteria for the very early diagnosis of systemic sclerosis: results of a Delphi Consensus Study from EULAR Scleroderma Trials and Research Group. Ann Rheum Dis. 2011;70:476-81.

54. Cordiali-Fei P, Mussi A, D'Agosto G, Trento E, Bordignon V, Trincone S, et al. Assessment of $T$ regulatory cells and expanded profiling of autoantibodies may offer novel biomarkers for the clinical management of systemic sclerosis and undifferentiated connective tissue disease. Clin Dev Immunol. 2013:2013:390563.

55. Lega JC, Cottin V, Fabien N, Thivolet-Béjui F, Cordier JF. Interstitial lung disease associated with anti-PM/SCl or anti-aminoacyl-tRNA synthetase autoantibodies: a similar condition? J Rheumatol. 2010;37:1000-9.

56. Marie I, Lahaxe L, Benveniste O, Delavigne K, Adoue D, Mouthon L, et al. Long-term outcome of patients with polymyositis/dermatomyositis and anti-PM-Scl antibody. Br J Dermatol. 2010;162:337-44.

57. Koschik 2nd RW, Fertig N, Lucas MR, Domsic RT, Medsger Jr TA. Anti-PM-Scl antibody in patients with systemic sclerosis. Clin Exp Rheumatol. 2012:30:S12-6.

58. Mehra S, Walker J, Patterson K, Fritzler MJ. Autoantibodies in systemic sclerosis. Autoimmun Rev. 2013;12:340-54.

\section{Submit your next manuscript to BioMed Central and take full advantage of:}

- Convenient online submission

- Thorough peer review

- No space constraints or color figure charges

- Immediate publication on acceptance

- Inclusion in PubMed, CAS, Scopus and Google Scholar

- Research which is freely available for redistribution 